\title{
State of Art Methodologies for Reducing the Carbon Foot-Print in Road Construction Industry: In India
}

\author{
Sameer Nema \\ Lafarge India Pvt. Ltd., Kolkata, India \\ Email: sameer nema@hotmail.com
}

Received 26 July 2015; accepted 15 August 2015; published 18 August 2015

Copyright (C) 2015 by author and OALib.

This work is licensed under the Creative Commons Attribution International License (CC BY). http://creativecommons.org/licenses/by/4.0/

(c) $\underset{\mathrm{EY}}{\mathrm{i}}$ Open Access

\section{Abstract}

Nowadays, carbon dioxide and different greenhouse emissions are one of the major causes to affect the climate change in the world. The Carbon foot print is commonly used to calculate the amount of different types of greenhouse gasses (GHG) emitted and carbon dioxide in the air. In road construction industry, the Carbon foot print is a very vulnerable issue, which is affecting economy and climatic condition of any nation. Therefore, the need to reduce the carbon foot print from our atmosphere through adoption of different optimizing techniques is a must. The life cycle approach has been accepted as a robust method of measuring carbon footprint. The road sector is coming under pressure to review current practice and the potential to reduce carbon emissions. This paper presents a review on state of art methodologies which needs to be adapted to reduced carbon footprint in the fast growing road construction industry due to increasing infrastructure demand. The ever increasing road construction will lead to increased carbon emission in the future decade especially when strong lobbying is for concrete roads in India, which have a much larger Carbon foot print as against Asphalt roads.

\section{Keywords}

Carbon Foot Print, Optimization, Green House Gases

Subject Areas: Civil Engineering, Environmental Sciences

\section{Introduction}

Carbon footprint is a term used to describe the quantum and to calculate the total amount of carbon dioxide $\left(\mathrm{CO}_{2}\right)$ and other green house gases (GHG) emissions for which an individual or organization is responsible. It is usually defined as the total amount of $\mathrm{CO}_{2}$ and other GHGs emitted over the full life cycle of a product or services for 
any industry. It can be calculated for activities, events or any such types of product which produce GHGs [1] particle in the atmosphere. It can be analyzed and calculated at the national or sector, corporate and household or individual levels.

Today, no sector can afford to ignore the ecological repercussions of its activities and the growing potential for enhancing positive, while reducing negative impacts. Representing around $15 \%$ of global greenhouse gas (GHG) and 23\% of energy-related carbon dioxide $\left(\mathrm{CO}_{2}\right)$ emissions (OECD 2010), the transport sector clearly has the scope and means to make a significant contribution in terms of championing more eco-friendly techniques and technologies. Alongside other industries, the road sector [3] has developed an array of emission assessment tools, as part of this endeavor and as an effective way to help translate into reality the low-carbon transportation strategies set up by governments. The road sector [4] is coming under pressure to review current practice and the potential to reduce carbon emissions.

This paper is part of an ongoing research work focused on calculation and reduction of CFP in road construction and begins to outline the state of art methodologies (life cycle approach) which needs to be adapted to calculate the CFP (carbon foot print) and the application of its results for reduction of CFP by use of sustainable road construction assessment schemes. It is the total amount of carbon dioxide and other GHGs (direct and indirect) emitted over the full life cycle of a road i.e. during the construction, operation, and maintenance phases which needs to be reduced in the booming infrastructure scenario.

\section{Structure of the Road}

Road construction is under four layer construction as per shown in Figure 1. In road construction the main materials are Aggregate, cement, bitumen etc.

After drying, the aggregate is typically heated to temperatures ranging from $280^{\circ} \mathrm{F}$ to $330^{\circ} \mathrm{F}$ and then coated with asphalt or cement in one of two ways. In most drum mix plants, the asphalt is introduced directly into the dryer chamber to coat the aggregate. In batch mix plants, the mixing of aggregate and asphalt takes place in a separate mixing chamber called a pug mil.

A composite pavement construction with $180 \mathrm{~mm}$ asphalt surfacing over $200 \mathrm{~mm}$ hydraulically bound base over $250 \mathrm{~mm}$ stabilized class 3 foundation was considered for the majority of the road length shown in Figure 1. This pavement option improved project resource efficiency compared with the conventional full-depth asphalt construction over granular sub-base. Stabilizing the foundation using local materials negated the need to import good quality aggregates and improved its bearing capacity, which led to reduction in pavement thickness and the associated resources use and lorry movement.

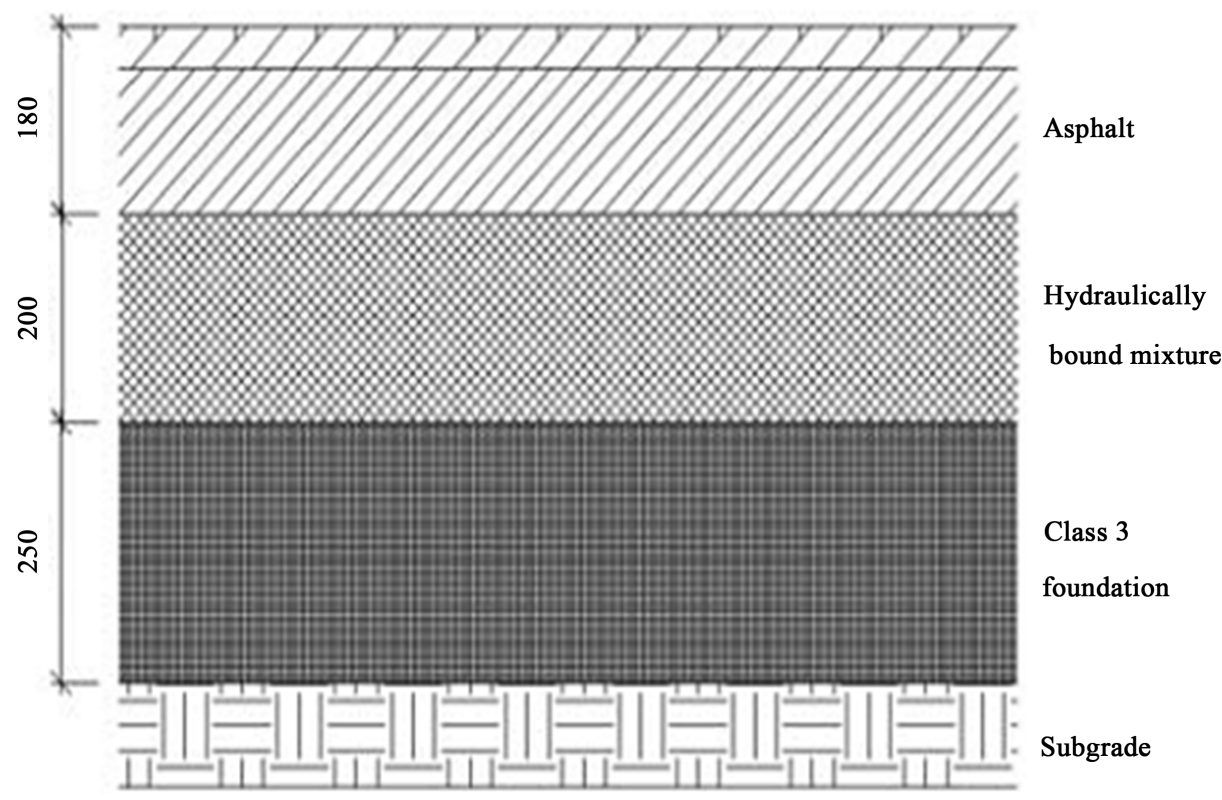

Figure 1. Basic structure of road [2]. 


\section{Life Cycle of Road Construction}

The life cycle of a road construction can be categorized into four phases as follows. Notably, transport is integrated in all phases, and the maintenance/rehabilitation activities repeat some, or all, of previous phases.

- Road Materials sourcing and its transportation

Raw materials sourcing and products manufacture (Figure 2)—Aggregates, Asphalt and concrete: Requires Transport of raw materials to Hot mix plant and hot mix products to construction site.

- Road Construction Phase-Hot Mix plant, Asphalt storage and heating tank, Construction on site, including machinery use and office hire.

Following Figures 3-5 shows the different steps for road construction.

- Road Operational Phase-The road operation is depends on maintenance and rehabilitation, including recycling or disposal of unserviceable materials. Figure 4 shows the operation of roads.

- Road Maintenance Phase-Repair of pot holes and patch repair of worn out surfaces.

\section{Green House Gases (GHG) Emissions Reduction}

Green house gases are the combination of sulfur oxide; Nitrogen oxide and carbon oxide gases. Here we discuss the ways on how to reduce the GHG emission in the atmosphere.

a) Sulfur Oxides Control:

This approach to reduce $\mathrm{SO}_{\mathrm{x}}$ emissions reduces the sulfur fed to the combustor by burning low sulfur fuels. Fuel blending is the process of mixing higher sulfur content fuels with lower sulfur fuels (e.g., low sulfur oil).

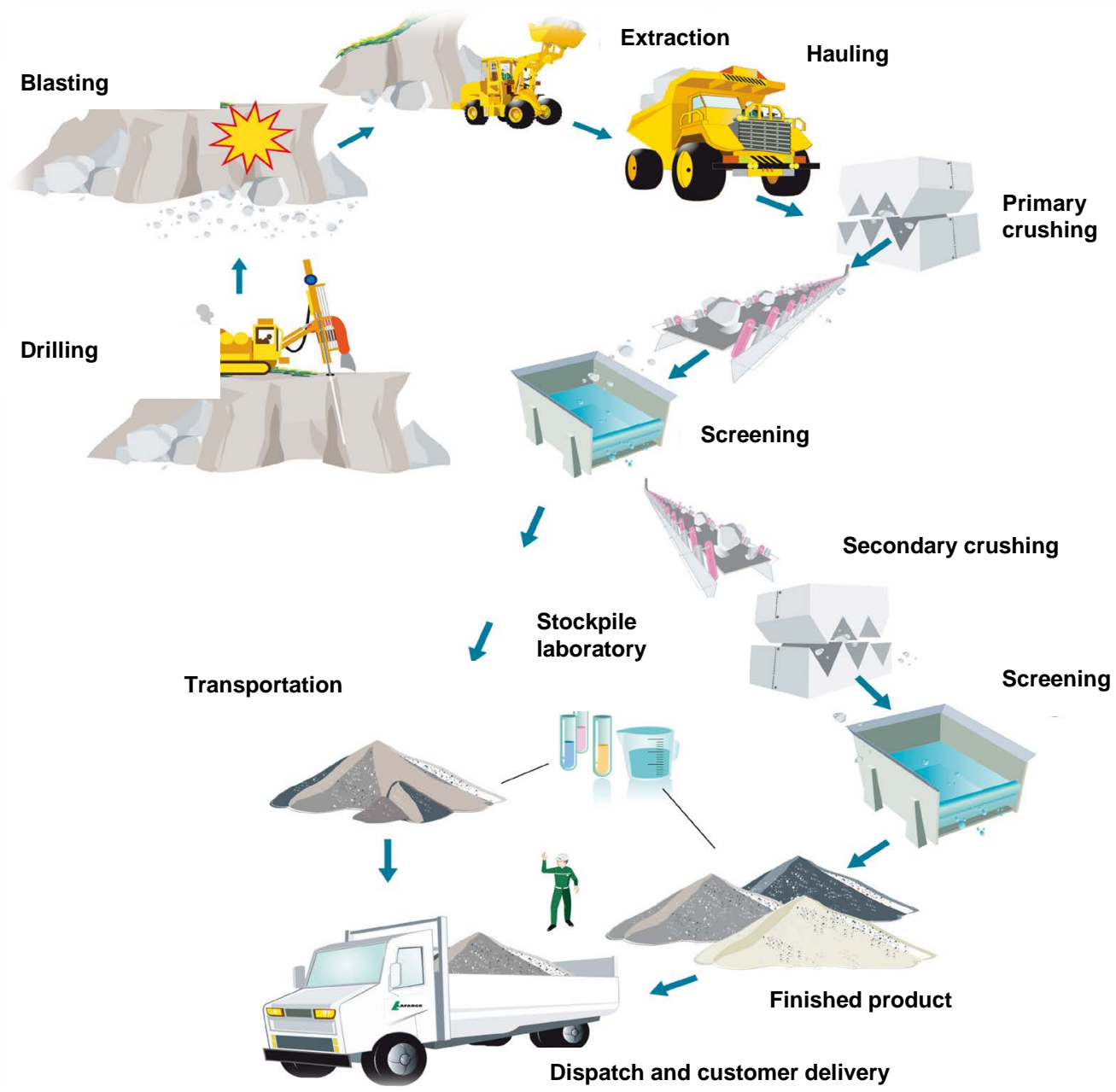

Figure 2. Raw material sourcing for road construction [5]. 

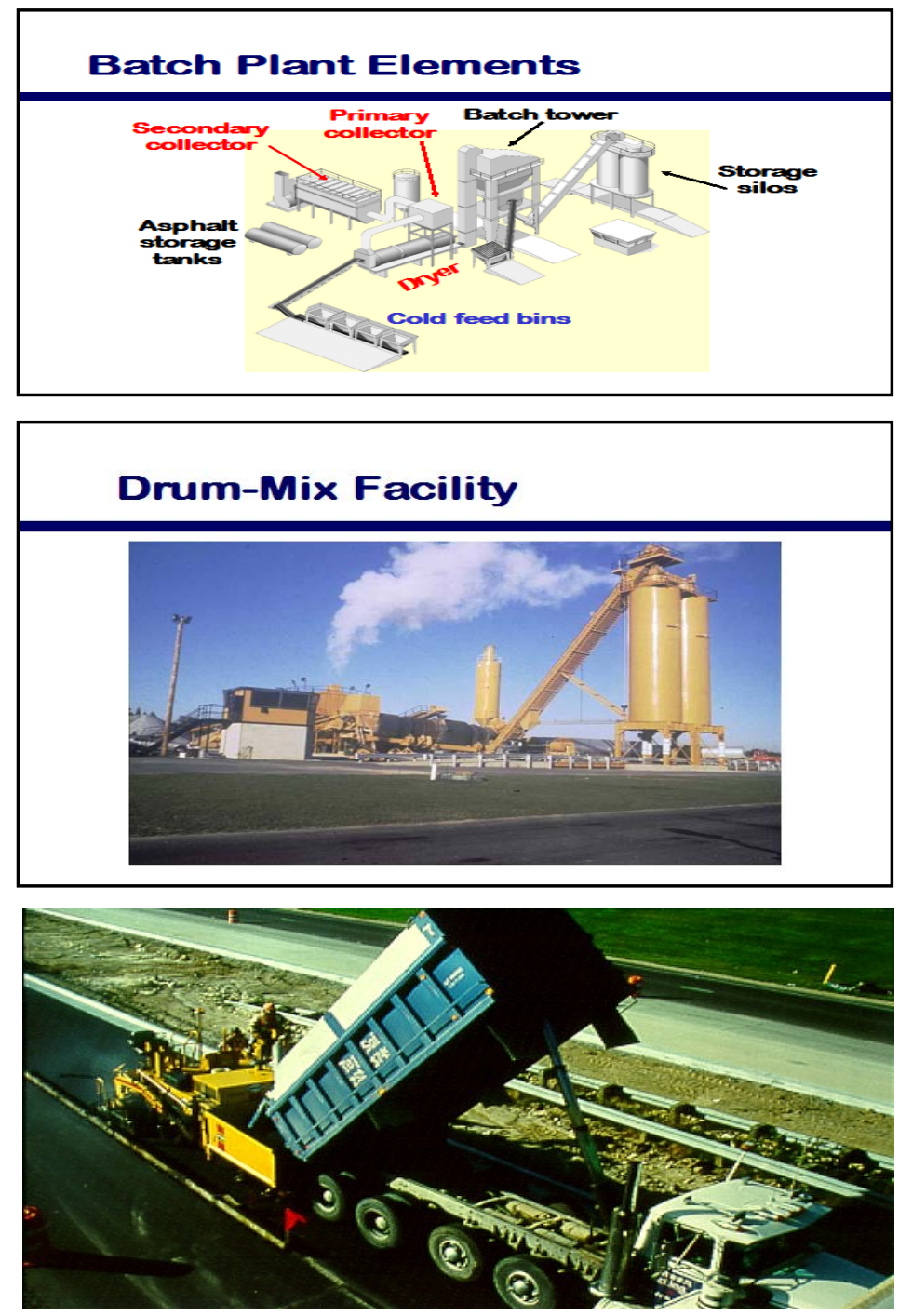

Figure 3. Different step of road construction phases [4].

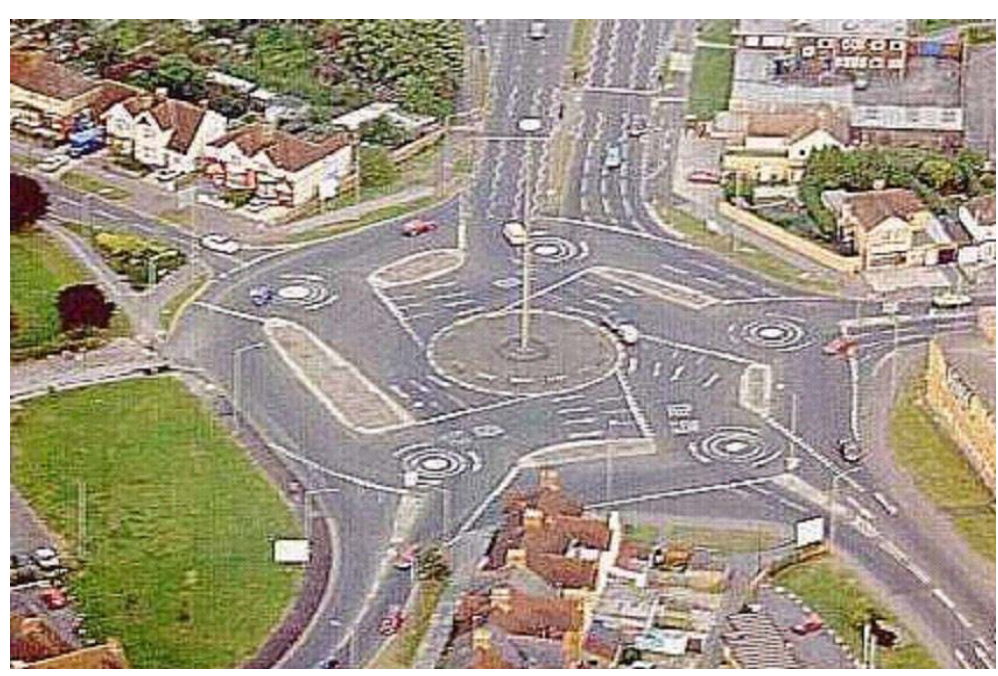

Figure 4. Operational phase of roads [5]. 


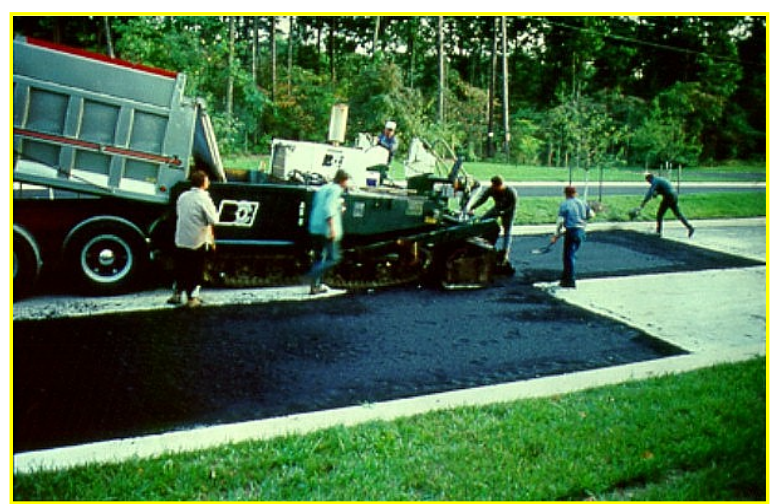

Figure 5. Road Maintenance phase [5].

The goal of effective fuel blending is to provide a fuel supply with reasonably uniform properties that meet the blend specification, typically including sulfur content, heating value, and moisture content.

b) Nitrogen Oxides Control:

Fuels lower in nitrogen content may reduce some $\mathrm{NO}_{\mathrm{x}}$ emissions (NAPA, 1995). At temperatures above $1300^{\circ} \mathrm{C}$, however, conversion from high-nitrogen fuels to low-nitrogen fuels may not substantially reduce $\mathrm{NO}_{x}$ emissions, as thermal $\mathrm{NO}_{\mathrm{x}}$ contributions will be more significant (Nevers, 1995). Consequently, $\mathrm{NO}_{\mathrm{x}}$ emissions are generally inversely related to $\mathrm{CO}$ emissions.

c) Carbon Oxide Control:

After burning the fuel or heating bitumen during road construction 30\% - 60\% carbon oxides (carbon mono oxide + carbon di oxide) are emitted. For reduction of these gases, we can use high grades or special type of bitumen for road construction. Also we can considerably decrease the temperature range from present $1300^{\circ} \mathrm{C}$. Below here in Table 1 we give the comparison of carbon emission in different stages of road construction.

After identifying the sources of $\mathrm{CO}_{2}$ emissions sources to be accounted, this helps while estimating the carbon footprint of a road as mentioned in Table 1. The detailed carbon footprint estimation model has been prepared. This model has three parts, namely road construction, road operation, and road maintenance.

\section{Methodology Used to Calculate the Carbon Footprint in Road Construction Industry}

The following methodological rules are used to calculate the carbon emission in different steps of road construction industry.

- Built-In Values,

- Suggested Values,

- User-Defined Values.

The method of calculation is derived from four main components of algorithms: emissions generated from materials, transport, and equipment.

The emission factors are drawn from internationally verifiable sources, including the Inventory of Carbon and Energy, the French Environmental Agency Ademe, various construction equipment producers, and the World Resources Institute.

Materials, equipment types, transport modes, and emission factors can be added and updated by the user.

Calculation consists of one predefined table for each GHG generator (materials, equipment, and transport) with multiple variables, including:

- Works Component: User specified characteristics and quantities or default values based on typical designs or works in East Asia; Customized based on project requirements;

- Characteristics: Variables providing basic characteristics about each GHG generator (material physical composition, equipment type, transport mode, origin, destination, etc.);

- Quantifying Data: Measurement values of each GHG generator (volume, weight, capacity, distance, fuel/ electricity type/consumption, etc.)

- Emission Factors: Kilograms of $\mathrm{CO}_{2}$ equivalents from verified source.

Layout diagram is shows the different parts of road construction industries in Figure 6. 


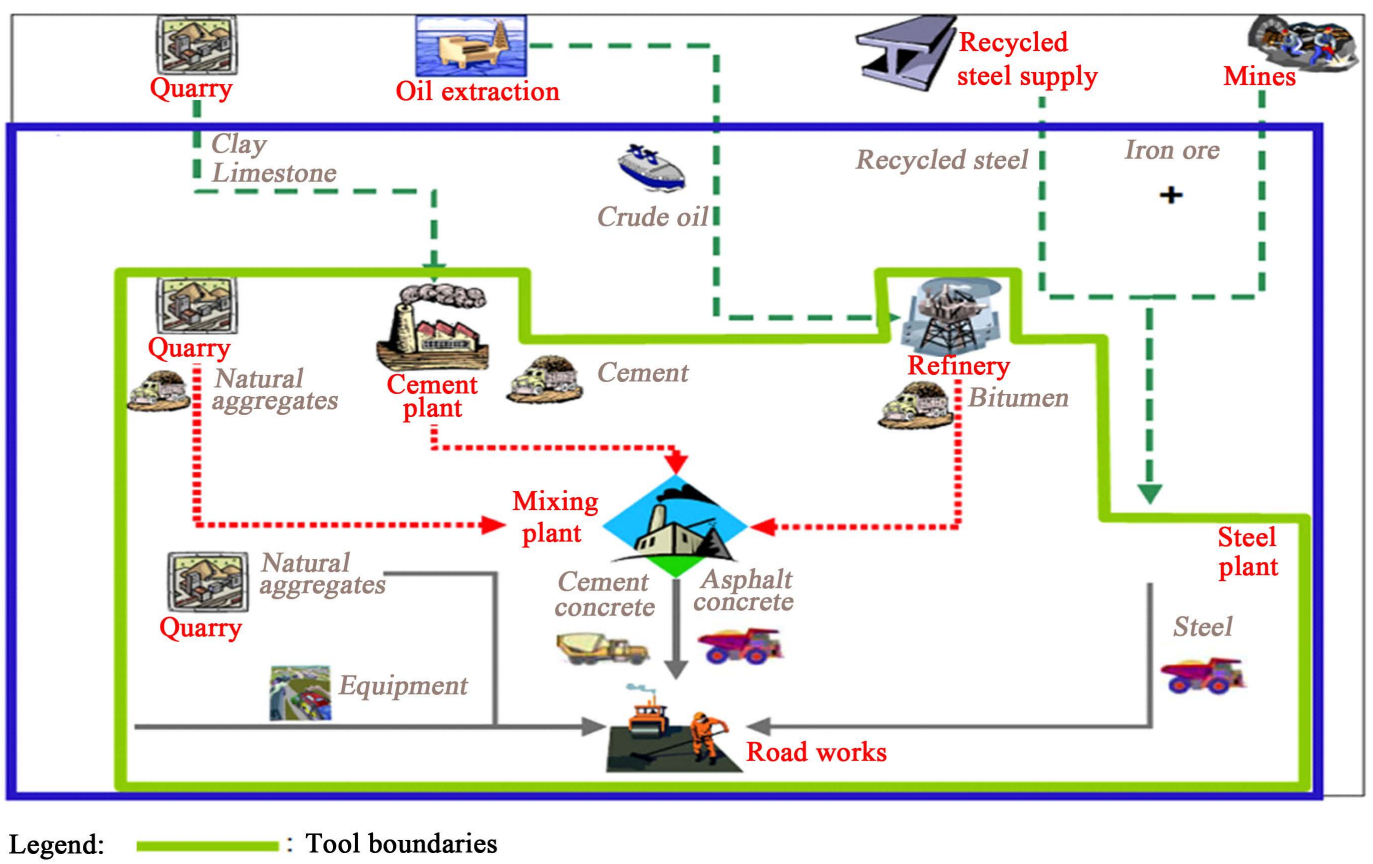

Figure 6. Different components of road construction industries.

Table 1. Comparison of carbon emission in different state of road construction.

\begin{tabular}{ccccccc}
\hline $\mathrm{CO}_{2}$ Sources & $\begin{array}{c}\text { Construction } \\
\text { Materials }\end{array}$ & \multicolumn{2}{c}{ Fossil Fuels } & Removal of Vegetation & Machinery/Vehicles \\
\hline $\begin{array}{c}\text { Road Life } \\
\text { Cycle Stages }\end{array}$ & $\begin{array}{c}\text { Embodied } \\
\text { Carbon }\end{array}$ & $\begin{array}{c}\text { Embodied } \\
\text { Carbon }\end{array}$ & $\begin{array}{c}\text { Direct CO } \\
\text { Emission }\end{array}$ & $\begin{array}{c}\text { Carbon Sequestration } \\
\text { potential lost }\end{array}$ & $\begin{array}{c}\text { Direct } \mathrm{CO}_{2} \\
\text { Emission }\end{array}$ & $\begin{array}{c}\text { Embodied } \\
\text { Carbon }\end{array}$ \\
\hline Road Construction & Yes & Yes & Yes & Yes & Yes & No \\
Road Operation & No & Yes & Yes & No & No & No \\
Road Maintenance & Yes & Yes & Yes & No & No & No \\
\hline
\end{tabular}

\section{Different Optimization Technique for Reducing the Carbon Footprint}

The international road federation (IRF) states that improving traffic fluidity, reducing congestion, and hence lowering fuel consumption is an effective way to reducing GHGs emissions, specific measures and their potential to reduce GHG emission are included in the following points.

- Enlarging the road network- $45 \%$ to $50 \%$.

- Replacing the crossroad by bridges about $-40 \%$.

- Building bypasses-30\%.

- Eliminate level crossings-15\%.

- Synchronized traffic lights-50\%.

- Traffic jam reduction-25\%.

- Management of urban traffic-40\%.

- Management of ex-urban traffic-30\%.

- Management of traffic on motorways-20\%.

The lifecycle approach has been accepted as a robust method of measuring carbon footprint. Tools and datasets have been developed to facilitate the measurement. Among them is the Calculator for Harmonized Assessment and Normalization of Greenhouse-gas Emissions for Roads (CHANGER) developed [a] by International Road Federation (IRF) and aimed to measure and benchmark the carbon footprint of road construction worldwide. 


\section{Conclusions}

The whole world is facing the global warming nowadays. Due to global warming, different environmental problem will raise i.e. heavy rain storm, heat wave, etc. The road construction industrial sector plays a major role to reduce the Green House Gas emission and also reduces the global worming effect. The other impacts associated with a road (e.g. leaching, fuming, noise), especially when recycled materials are increasingly used, should not be traded off for GHGs. Companies have taken action for environmental labeling need to ensure that their pursuit of "green" construction is not simply based on a single aspect such as $\mathrm{CO}_{2}$ saving.

For making $1 \mathrm{~km}$ of a $3.5 \mathrm{~m}$ wide user road path, 342 tons of concrete is used. But if concrete is replaced by asphalt for same distance user road path, only 55 tones asphalt is sufficient to complete the project. Thus the estimated cost is also reduced. Also 80\% reduction in green house emission if we are using Asphalt instead of concretes and we can say that the $80 \%$ - $85 \%$ carbon footprint may be reduced.

\section{References}

[1] Hakimb, B., Zammataroc, S. and Huanga, Y. (2009) Measuring the Carbon Footprint of Road Construction Using CHANGER. International Journal of Pavement Engineering-Taylor and Francis, NREL US Life-Cycle Inventory Database, National Renewable Energy Laboratory.

[2] Huang, Y. (2007) Life Cycle Assessment of Use of Recycled Materials in Asphalt Pavements. Ph.D. Newcastle University.

[3] Marland, G., Boden, T.A. and Andres, R.J. (2007) Global, Regional, and National $\mathrm{CO}_{2}$ Emissions. In Trends: A Compendium of Data on Global Change, Carbon Dioxide Information Analysis Center, Oak Ridge National Laboratory, US Department of Energy, Oak Ridge.

[4] (2006) A Life Cycle Perspective on Concrete and Asphalt Roadways: Embodied Primary Energy and Global Warming Potential. Athena Institute, Ottawa.

[5] http://www.shell.com/ 